\title{
Tópica, analítica e direito: reflexões para o jurista contemporâneo.*
}

\author{
Dimas Salustiano da Silva**
}

Sumário: Introdução: linguagem, direito e poder; 1. Linguagem, direito e história; 2. Tópica, Analítica e o logos da filosofia ocidental; 3. Racionalidade aristotélica: articulação e complemento; 4. Racionalidade prática: justiça e tópica; 5. Padronização, unidade e ruptura no direito; 6 . Alternatividade ou insurgência no direito dos excluídos; 7. Para concluir.

Nestes últimos anos,

Nada de novo há

no rugir das tempestades.

Não estamos alegres, é certo.

Mas também porque razão

haveriamos de ficar tristes?

O mar da História é agitado.

(Maikowsky)

\section{Introdução: linguagem, direito e poder}

As palavras não possuem significados unívocos. Esta afirmativa sem dúvidas proporciona que sejam levantadas uma série de questões caras à Ciência do Direito. Mormente quando a semiologia encontra com freqüência nos dias de hoje, lugar nas preocupações, só para citar alguns juristas dedicados à problemática no Brasil, podem ser mencionados Luís Alberto

* Discurso proferido na abertura da Semana do Advogado, simpósio realizado em homenagem ao Prof. Francisco Muniz ertre 07 e 11 de agosto de 1995, pela Faculdade de Direito da UFPR, Ordem dos Advogados do Brasil - Seção do Paraná e Partido Democrático Universitário (Centro Acadêmico Hugo Simas).

** Prof. de Direito Constitucional da Universidade Federal do Maranhão. Mestrando em Direito Constitucional na Universidade Federal do Paraná. Advogado.

R. Fac. Direito, Curitiba, a.28, n.28, 1994/95, p. 189-210 
Warat ${ }^{1}$ e os brasileiros Paulo de Barros Carvalho, ${ }^{2}$ Tércio Sampaio Ferraz, ${ }^{3}$ e antes ainda, na pena de Lourival Vila Nova. ${ }^{4}$

Não é pretensão deste trabalho, adentrar nesta seara, ocorre que não podem passar despercebidos alguns achados teóricos, para compreender quão importante é a palavra no campo do direito, relegada muita das vezes nas grades curriculares da Academia, quando muito ao âmbito da oratória, e mesmo no interior desta, como mero exercício sofístico.

Dessarte, mesmo em Escolas de matiz conservador no país, como a velha e digna Faculdade do Recife, de chofre identificada sob o rótulo de dogmática, extrai-se dentre seus mestres de maior calado, notas sobre o tema como a seguinte:

"É certo que a análise fenomenológica opera tendo por modelo das proposições descritivas de objetividades (objetividades reais e ideais). Por isso, quando coloca fora de tema a conseqüência - (o ser implicado) e os valores-de-verdade - para isolar somente o gramatical puro, o apriori sintático das formações de significado - tem em vista as proposições teoréticas ou as não deônticas. Só provisoriamente deixam de ser fim temático a verdade e a falsidade das proposições, mas para elas se encaminha a investigação, detida no estágio do ter sentido ou do carecer de sentido". ${ }^{5}$

1 Luís Alberto Warat, $O$ direito e sua linguagem, Porto Alegre, Fabris, 1984.

2 Paulo de Barros Carvalho, Curso de Lógica Jurídica, Salvador, Fundação Universidade Federal da Bahia, 1991.

3 Tércio Sampaio Ferraz Junior, Direito, Retórica e Comunicação, São Paulo, Saraiva, 1973, e ainda do mesmo autor, Teoria da Norma Juridica, Rio de Janeiro, Forense, 1986 e Introdução ao Estudo do Direito: Técnica, Decisão, Dominação, São Paulo, Atlas, 1988.

4 Lourival Vilanova, Lógica Jurídica. São Paulo, Bushatsky, 1976, e também, Estruturas lógicas e o sistema de direito positivo, São Paulo, EDUC/ RT, 1977.

5 Lourival Vilanova, Lógica Jurídica, p. 149 - 50, onde ainda o autor ao seu modo ensina: "É a lógica-instrumento com que trabalha o jurista teórico ou prático, cujo objetivo não é fazer lógica, mas relacionar o logos com a concreção existencial, de onde procede e para onde se dirige o direito, como instrumento cultural destinado a estabelecer um tipo de ordenação na vida humana coletiva. Essa atitude retrovertida(a reflexão husserliana) para o logos, pondo entre parênteses metódico a existência mesma dos fatos e dos valores (axiológicos digamos) não foi nem pode ser a atitude dos juristas com senso da realidade. Foi teorização, excesso racionalista, cujo fundo subjacente o sociólogo sabe descobrir. E descobrir como ideologia que quer se confundir com ciência, falsa consciência que Kelsen implacavelmente sempre denunciou", p. $169-170$. 
Se para Vilanova, o gramático puro repercute no nível de um apriori sintático das formações de significados, em Tércio Sampaio no seu Teoria da Norma Jurídica pode ser dito que a linguagem possui um viés comunicativo, onde aquele autor entende o discurso normativo de acordo com a teoria da comunicação, na qual a norma jurídica aparece como regulativa dos conflitos surgidos nas interações sociais, assumindo o lugar de terceiro comunicador, onde funciona como mediador ou árbitro, caracterizando assim, uma interação peculiar que privilegia o comunicador normativo, personalizado nos juízes e nos legisladores, a quem compete a decisão, solucionando os conflitos não porque os elimine de fato, mas que lhes põe um fim segundo procedimentos formais legalmente cogitados, decidida a questão esta não pode mais ser levantada. Estamos no plano das abstrações da coisa julgada, desse raciocínio, temos que a decisão judicial está no terreno da pragmática, e não mais, na posição de harmonizadora do conflito social, vez que longe de eliminá-los, somente os encerra e os transforma.

O direito não está imune ao estatuto do político. Nessa direção Warat demonstra que há um certo esgotamento da produção lingüísticosemiológica atual dos juristas e busca indicar um novo ponto de vista que designa enquanto semiologia do poder, em relação a qual o direito está preponderantemente implicado, sobre o qual diz:

"Uma análise política do conhecimento jurídico pode demonstrar como os pontos de vista imanentes e formais. que comandam a produção da cultura juridicista, não expressam insuficiências metodológicas, mas funções sociais específicas, contribuindo para o estabelecimento de um marco de coerção e controle "racional". Tal marco contribui para que a "forma" materialize o encobrimento das relações sociais. Eis uma parte do poder da significação jurídica". ${ }^{6}$

É possível verificar a partir desses mais variados padrões de explicação vinculados à teoria da linguagem aplicada ao direito, o quanto é importante a significação simbólica para a Ciência Jurídica e o grau de imbricação com o poder nas suas mais variadas faces. No entanto, aos ouvidos dos juristas, muita das vezes podem soar estranhas as palav ras de um intelectual do porte de Rolan Barthes, na sua aula inaugural da cadeira

6 Luís Alberto Warat, $O$ direito..., op. cit., p. $102-103$.

R. Fac. Direito, Curitiba, a.28, n.28, 1994/95, p.189-210 
de semilogia literária do Colégio de França, pelo caráter aberto e inovador que confere ao tema :

"Esse objeto em que se inscreve o poder, desde toda eternidade humana, é: a linguagem - ou, para ser mais preciso, sua expressão obrigatória a língua. A linguagem é uma legislação, a língua é seu código. Não vemos o poder que reside na língua, porque esquecemos que toda língua é uma classificação, e que toda classificação é opressiva...

Ou mais precisamente, o que está a nos fornecer Barthes são os intricados contornos característicos do poder, que por sua vez está umbilicalmente ligado à linguagem, que assim prossegue:

...Adivinhamos então que o poder está presente nos mais finos mecanismos do intercâmbio social: não somente no Estado, nas classes, nos grupos, mas ainda nas modas, nas opiniões correntes, nos espetáculos, nos jogos, nos esportes, nas informações, nas relações familiares e privadas, e até mesmo nos impulsos liberalizadores que tentam contestá-lo: chamo discurso de poder todo discurso que engendra o erro e, por conseguinte, a culpabilidade daquele que o recebe. Alguns esperam de nós, intelectuais, que nos agitemos a todo o momento contra o poder, mas nossa verdadeira guerra está alhures: ela é contra os poderes, e não é um combate fácil: pois, plural no espaço social, o poder é simetricamente, perpétuo no tempo histórico: expulso, extenuado aqui, ele reaparece ali; nunca perece; façam uma revolução para destruí-lo, ele vai imediatamente reviver, regerminar no novo estado de coisas". ${ }^{7}$

Consoante essas compreensões relacionais, de um certo modo díspares entre poder e linguagem, é possível identificar como ponto comum o fato de engendrar uma recondução necessária ao direito, com reflexos quanto ao seu próprio estatuto enquanto Ciência. Retornando ao início do texto quando se afirma que as palavras não são unívocas, é necessário esclarecer que dessa assertiva advém a necessidade de mergulharmos numa espécie de "arqueologia" do saber, a partir da qual é possível identificar de que modo certas noções conceituais sedimęntaram-se no repertório do senso comum dos juristas.

7 Roland Barthes, Aula..., São Paulo, Cultrix, 1978, p. 11-12. 
Por isso mesmo, torna-se ingente buscar a gênese dos termos "dogmatica" e "crítica" jurídicas, sem todavia caírmos no retorno a estéril discussão entre Escolas "Positivistas" e do "Direito Natural". Mediante tal pensamento, é na Grécia de Aristóteles que vamos buscar as razões do apartamento entre o prático e o teórico, com prejuízos ao primeiro, e para as ciências oriundas dos valores ocidentais como um todo, pois que, na verdade tratam-se de dois momentos indesvencilháveis do mesmo processo de elaboração do conhecimento humano.

As palavras articuladas aos seus significantes permitem que possam ser pensadas a partir de conteúdos semânticos vários, o que implica de passarmos a tratar a linguagem científica em geral e a da teoria do direito no particular como possuidora de sentidos mutantes e numa perspectiva muita mais conotativa que denotativa.

Esta postura diante da Ciência do Direito está longe de ser majoritária, mas incomoda, mesmo que não se constitua numa ameaça a hegemonia do tecnicismo juridicista. Porém, o seu mérito reside em colocar em xeque os paradigmas de objetividade e pureza, até então vigentes na Ciência Jurídica, todavia, necessita ainda de maior rigor e melhor precisão nos seus métodos. Importante base para compreender os mais diferentes estágios evolutivos das palavras, conceitos e noções, temos como uma das pistas possíveis o terreno da linguagem, ou melhor da sua teoria, locus onde os signos, os aspectos do simbólico adquirem proeminência. Do qual ilações mais firmes desautorizam aduzir sobre a neutralidade do discurso jurídico, ou mesmo da própria língua como já foi possível notar nas enunciações do pensamento barthesiano.

Agora, o que precisa ser melhor expressado e principalmente melhor escutado, é que no mesmo rumo das pegadas de algumas teorias ditas de salvação dos oprimidos, que não satisfazem o universo problematizante dos países pobres como é o caso brasileiro, tais articulações com a linguagem, com o direito e o poder, em sua maioria não passam de meros padrões de explicação. Criadas no primeiro mundo, que não obstante, uma pretensão universalizante e adotadas qui sem maiores "senões", seus vetores de investigação foram dirigidos à realidade dos países ricos, como é possível ver em Dussel:

"O que esses modelos esquecem é que o pressuposto é uma enorme tautologia sistemática. Ou seja, aceita-se ingenuamente que a informação

R. Fac. Direito, Curitiba, a.28, n.28, 1994/95, p. 189-210 
possa ser decodificada, que não existam conflitos lingüísticos, sociais, políticos, eróticos..."

Adendaria ao pensamento de Dussel, mais um tipo de conflito de explosiva repercussão contemporânea que é o da etnicidade, não só porque pressupõe língua e costumes desiguais, mas substancialmente pelo ocultamento de verdadeiras nações coexistindo em espaços comuns, continuando:

Aceita-se obviamente, depois de numerosas abstrações que o comunicólogo sempre esquece (o que o leva a confundir as estruturas abstratas com as estruturas reais da comunicação), o sistema vigente, freqüentemente dominador, no qual, todos dizem interpretar o que se diz, embora na realidade não possam explicar o sentido de nada do que se diz". 8

\section{Linguagem, direito e história}

O fato é que nos encontramos de algum modo, no transcurso de uma infindável viagem, com a máquina do tempo como a que nos perseguir, somos reféns nesse ponto do pensamento benjaminiano. Mais precisamente da sua alegoria clássica, inspirada num quadro de Klee: a de que há um anjo pairando sobre nós todos, o angelus novus da História, que mantém o rosto dirigido para o passado, deseja deter-se para salvar os mortos, mas uma incrível tempestade chamada progresso, vinda do paraíso, sopra sobre suas asas e o impele inexoravelmente para o futuro. Eis-nos perante uma frágil certeza, pode-se até indagar, sobre de qual progresso que estamos a nos referir? entretanto, colocados sob a irrefutabilidade da história enquanto um dinâmico processo, sucumbimos e acatamos na condição de passageiros seus, e, ao mesmo tempo como timoneiros também. ${ }^{9}$

Destarte, parece adequado referirmo-nos sobre o tema num sentido renovado, haja vista que ao tomarmos como ponto de partida o meio da

8 Enrique Dussel, Filosofia da Libertação na América Latina, São Paulo, Loyola, 1980, p. 128.

9 Sérgio Paulo Raounet, As Razões do Iluminismo, São Paulo. Companhia das Letras, 1987. p. 43. 
viagem, utilizando-se da desgastada fórmula dualista positivismo versus jusnaturalismo, advém a sensação do uso de molduras lingüísticas vinculadas aos anos oitocentos. De certo, com fortes ressonâncias atuais, ainda que no pórtico do século XXI. Entrementes, não apenas por isso, sobretudo pelas práticas veladas da negação de dois momentos que embora distintos são inseparáveis, por estarem assentados em uma mesma base epistemológica, estamos a nos referir aos instantes metódicos da tópica e da analítica encontrados no pensamento aristotélico.

Eis-nos diante das "palavras viajantes", que nos reconduz a uma "arqueologia dos conceitos", ${ }^{10}$ isto é, o mesmo vocábulo adquire sentidos cambiantes, outro caso diferentemente, seriam de palavras distintas para designar sentidos análogos ou pelo menos assemelhados. Explica-se assim o título, no qual recorre-se aos argumentos gregos e também com um significado mutante a essa argumentação contemporânea da alternatividade, que ao final preferimos por denominar como de movimento do direito insurgente.

A possibilidade de uma articulação entre direito, linguagem e história é perfeitamente assimilável, quando nos reportamos, mais uma vez às reflexões de Dussel:

"A relação do significante (por exemplo, palavra) ao significado (o sentido, que se comporta como significante intencional com relação ao significado real: a própria coisa em alguns de seus aspectos) é a semântica. Todo significante tem uma denotação ou um referente imediato (o sentido), e uma conotação uma respectividade por último ao mundo. O que acontece é que o mesmo sentido é respectivo ao mundo e, por isso, toda denotação de algo é conotativa por último da totalidade do mundo, Da mesma forma, pela mobilidade semântica do significado (que vai mudando de sentido num mundo que é histórico), o significante já não significa de todo no presente o seu significado, mas só parcialmente. A mutabilidade do significado é o que constitui a possibilidade da história das línguas". ${ }^{11}$

10 José Joaquim Gomes Canotilho, Direito Constitucional, Coimbra, Almedina, 1992, p. 12.

11 Enrique Dussel, Filosofia..., op. cit., p. 126

R. Fac. Direito, Curitiba, a.28, n.28, 1994/95, p. 189-210 


\section{Tópica, analítica e o logos da filosofia ocidental}

Algumas pistas podem ser encontrados nas reflexões do aluno mais eminente de Platão na Academia, este por diversas vezes rompe com seu mestre e acaba por inaugurar um pensamento singular, pois o discípulo vai além. Seus trabalhos mais importantes, são sem dúvida "A Política", "A Retórica" e "Ética a Nicómaco", nos quais dá-nos as idéias sobre a essência e o fim do homem, como não poderia deixar de ser o homem bem como todas as coisas em Aristóteles possuem uma essência, eis porque é legítimo incluí-lo no paradigma do ser, assumindo pois, uma dimensão ontológica. Ademais, pode ser dito ainda sobre o estagirita que seu pensamento é teleológico uma vez que a essência das coisas por definição corresponde sempre a uma atividade, esta por conseqüência está determinada por um fim, a finalidade para os gregos inclui necessariamente $o$ ser como realizado, vivendo em estado de felicidade, patamar este alcançado no ambiente privilegiado da pólis.

Para o mundo grego no qual está incluída a pólis e por conseqüência o cidadão, o essencial do humano está centrado com precisão no ato deste dever, buscar a felicidade na sua auto-realização pelo pensamento, na vida intelectual, teórica, política e filosófica, eis portanto, o seu quid enquanto humano.

Apesar disso, é na "polêmica" travada entre Parmênides e Heráclito que a prevalência do viés ontológico vai afirmar-se decisivamente, com profundas repercussões em toda a teoria do conhecimento ocidental. Não obstante as teses diametralmente opostas observadas em Heráclito de Éfeso que:

"acreditava num mundo em perpétua mudança, de um eterno 'vir a ser'. Para ele, todo ser estático baseava-se num logro; seu princípio universal era o fogo, um símbolo para o contínuo fluxo e a permanente mudança em todas as coisas. Heráclito ensinava que todas as trasformações no mundo derivam da interação dinâmica e cíclica dos opostos, vendo qualquer par de opostos como uma unidade. A essa unidade que contém e transcende todas as forças opostas, denominava logos". ${ }^{12}$

12 Fritjof Capra, O Tao da Fisica, São Paulo, 1984, p. 23-24 
Em rumo inverso, Parmênides de Eléia denominava seu princípio básico como o ser, afirmando-o único e invariável. Considerava impossível a mudança encarando aquelas que presumimos perceber no mundo como simples ilusões dos sentidos. O conceito de uma substância indestrutível como sujeito de propriedades diversas originou-se dessa filosofia, vindo mais tarde tornar-se um dos conceitos fundamentais do pensamento ocidental. $^{13}$

Destarte, a partir desses dois eixos é legítimo concluir que Parmênides "instaura o começo da filosofia como ontologia : "O ser é, o não-ser não é". O ser é tido como o fundamento dos entes. O fundamento do mundo. O que não é ser, não é. É o nada. O ser não é pensado, compreendido como um fundamento distante e isolado do mundo. Ao contrário, o ser como fundamento significa que o mundo, os entes, as coisas (tà ónta), os úteis (tà pràgmata) são vistos, porque iluminados por ele. Ser e mundo coincidem". ${ }^{14}$

Para Aristóteles, apesar das diferenças em relação a Parmênides, tem neste, como que um substrato comum, este para aquele é por assim dizer uma catapulta paradigmática. Implica afirmar que o aspecto ontológico é igualmente momento marcante que aos dois pensadores acaba por enredar no mesmo paradigma - o do ser - . A epistemologia aristotélica pode ser entendida, deduzindo do seu pensamento, o princípio primeiro onde a realidade se confunde com a substância das coisas, e decorrentemente, a essência bipartida encarada como dois momentos de um mesmo processo de apreensão da verdade.

Tal articulação permite-nos entender a essência das coisas, primeiramente, como instante onde é extraída qualquer referência ou qualidade que um objeto possa ter ou não, como decorrência teríamos o plano do sensível, fonte de todos os nossos conhecimentos tidos como verdadeiros, porém despossuídos do status científico. De outro modo, há concomitantemente uma essência necessária, que operando por exclusão, enuncia o que a coisa não pode ser e que constitui-se no porque da própria coisa, nessa perspec-

13 Ibidem, p. 24.

14 Celso Ludwig, A Alternatividade Jurídica na Perspectiva da Libertação, Curitiba, 1993, mimeo, p. 10.

R. Fac. Direito, Curitiba, a.28, n.28, 1994/95, p.189-210 
tiva estaríamos no plano do intelectivo, seria definido como ato de abstrair, ou retirar pela inteligência, o conteúdo inteligível, incluso na realidade física sensível, nesta hipótese tem-se um conhecimento que além de verdadeiro é científico, a essência das coisas pelas causas, algo de necessário e universal.

Para Cabrál de Moncada Aristóteles: "Meteu, por assim dizer, as Idéias platônicas dentro das coisas e fundou deste modo aquilo a que se pode chamar uma teoria imanentista das primeiras. Segundo ele, portanto, na sua ontologia metafísica, as Idéias deixam de existir separadas das coisas num mundo transcendente inalterável, e passam a existir e a viver no interior das próprias coisas e realidades sensíveis". ${ }^{15}$

Uma importante repercussão pode daí ser extraída, qual seja, a de encarar o nosso saber como conceitos e o ser como formas. Há, porém, coincidência e harmonia, consistindo essa adequação no realismo epistemológico aristotélico.

A abordagem até aqui feita, refere-se ao logos teórico de Aristóteles. Segundo o qual, a razão teórica tem por função contemplar os primeiros princípios invariávies das coisas. Assim, o objeto da faculdade racional (dessa razão teórica) é a fysis, passível de obter-se acerca deste objeto (fysis) um conhecimento nos moldes acima abordados.

\section{Racionalidade aristotélica: articulação e complemento}

O pensamento de Aristóteles admite, porém, a existência de outra faculdade: a calculativa ou deliberativa. É a que se ocupa daquilo que não é necessariamente. Pois, não se pode deliberar acerca do que é. A razão prática tem por objeto não a fysis, mas a contemplação daquilo que é possível de variações. Ambas as razões visavam a percepção da verdade, no entanto, o "logos prático" deve contentar-se com um conhecimento menos preciso, de menor rigorosidade.

15 Cabral de Moncada, Filosofia do Direito e do Estado, Saraiva, São Paulo, 1950, p. 27-28. 
Tem-se nesse aspecto uma distinção da idéia de ciência, para os gregos por excelência a matemática, por isso seria possível afirmar de que a um geômetra deve-se exigir demonstrações rígidas, sentenciais, não apenas prováveis, uma vez que encontra-se no campo do "logos teórico". Porém, o mesmo não pode ser esperado de um orador, que por sua vez está no âmbito do "logos prático". A razão prática tem, portanto, a função de conhecer a atividade humana que faz parte das "coisas passíveis de variação". Distingue-se, por conseqüência, da realidade teórica nos aspectos agora vistos.

A racionalidade de Aristóteles até então analisada, não nega na atividade humana a racionalidade, muito ao contrário, combina-as, a atividade tem sentido prático, e, não única e exclusivamente sentido teórico. $\mathrm{O}$ que há de pragmático desta racionalidade é o sentido de apoio, suporte, de ajuda. Conhecer os bens ou o bem supremo que estaria na felicidade, como comentado dantes, implica necessariamente em poder fazer o homem melhor, e também numa atividade mais otimizada enquanto práxis ou poiésis, respaldada num inquebrantável liame entre teoria e prática. Advém como finalidade então, não somente o conhecimento da felicidade, mas amoldar o homem de um novo tipo, mais feliz. Um homem para além de mero conhecedor do que seja Justiça, mas transformado em ser humano mais justo.

Tal discussão não adquire dimensão apenas no campo da Ciência Política, no campo da Teoria do Direito e da Ciência do Direito Constitucional adquirem prevalência, muito embora com maior importância para primeira, uma vez que local privilegiado de abrangência da Ética e da Política propriamente dita. Do até então visto, a Ética encontra seu lugar na teoria aristotélica no campo da razão prática, uma vez que a Justiça é uma virtude ética, e por conseqüência a noção de verdade jurídica deve ser perquirida nos limites e segundo os critérios do "logos prático" essencialmente, buscando o investigador ou operador do direito apenas sustentação do seu trabalho no "logos teórico".

Ocorre que exatamente neste ponto o pensamento de Aristóteles pode ser revisitado em função dos métodos por ele criados, a exemplo de conceitos e formas, o apodítico e o tópico longe de serem excludentes, são inseparáveis e complementares.

R. Fac. Direito, Curitiba, a.28, n.28, 1994/95, p. 189-210 
A tópica, ou método dialético (bem diferente do sentido moderno que o termo hoje possui), é anterior ao científico, partiria das "opiniões gerais", ou como prefere Enrique Dussel "pelo compreendido cotidianamente", para se referir a ex endóxon. Por esse raciocínio é fundante a todas as ciências. é o factum primeiríssimo, ponto de partida para exibir os princípios de todo o saber, este momento porém, compreende o mundo histórico e concreto dos homens, discrepa dos sofistas uma vez que não é mera refutação, importa antes de mais nada no achado do argumentum, há uma preponderância do opinável. Ocorre que esta perspectiva aristotélica. foi deliberadamente condenada ao esquecimento, posta à margem, resta escondida a existência de um conhecimento que é anterior há um saber demonstrativo.

Nos analíticos ou apodícticos, prepondera o método da demonstração por silogismos, é possível relacionar os primeiros com a essência primeira das coisas, aqui a vinculação é com a essência necessária, ou mesmo substância. De onde, a ciência não parte das possibilidades, mas de um princípio ou axioma, de uma hipótese verdadeira. O saber científico não problematiza ou lança indagações acerca de seus axiomas, que são pressupostos como verdadeiros e científicos. Parte da consideração que são evidentes do contrário não haveria ciência.

\section{Racionalidade prática: justiça e tópica}

Aristóteles não tinha uma noção de direito tal qual conhecemos mais modernamente, a significação mais aproximada estava assentada no vocábulo "dikê", filha de Zeus e de Themis representativa da personificação da Justiça. Note-se que o termo leva a encarnação da idéia na própria coisa, derivando assim, "dikaion" para se referir ao justo, ou ainda, "dikazein" aludindo ao julgar bem, com retidão. ${ }^{16}$

A ética aristotélica é um vetor dirigido à virtude, possui uma dimensão moral que lhe é imanente e que perpassa qualquer noção de direito, uma vez que vincula a pólis enquanto criadora, executora ou aplicadora das leis e mesmo os cidadãos no sentido de observá-las. A Justiça está relacionada

16 Ruth Guimarães, Dicionário da Mitologia (Irega, São Paulo, Cultrix, 1991, p. 127. 
com uma disposição de caráter, mais uma vez o discípulo rompe com seu mestre Platão, a Justiça não é uma idéia, está intrinsecamente no próprio homem, jamais com existência autônoma, em si mesma e transcendental.

A Justiça encarada como a mais proeminente das virtudes é entendido de um modo geral. latu sensu como sendo a virtude completa por excelência. na qual estariam as virtudes sociais, observe-se que as partes não formam o todo, mas é a cosmologia da fysis que contém a pólis e que para sua garantia e sustentação depende o cidadão virtuoso.

De um modo particular, como parcela da virtude mais ampla que pode ser dividida em duas, encontra-se a justiça distributiva onde prevalece como critério formal a proporção, orientador da distribuição entre aqueles que têm parte no todo. Importa na relação entre a pólis e os cidadãos, o slogan que a caracteriza é "A Cada um segundo o seu mérito". aqui são repartidos os bens e honras públicas, segundo elementos materiais da necessidade, capacidade e mérito.

A segunda, chamada de justiça sinalagmática ou corretiva, cujo critério formal é a igualdade, numa dimensão aritmética, reveste-se na fórmula "Que cada um naquilo que dá ou que recebe, receba ou dê um valor objetivamente igual ao da prestação da outra parte", podendo ser sub-dividida em comutativa e judiciária, sendo que na primeira estão localizadas as relações com liberdade de troca, tendo por objeto coisas de valor exato e determinável, é o campo dos negócios e contratos, a segunda diz respeito a exigência da presença de um juiz, nos casos por exemplo de cometimento de um ilícito, ensejador de obrigação, e ou, reparação de dano.

Essa justiça para Aristóteles ainda que imbricada pela Tópica e Analítica, tendo-se sempre em mente o cuidado metodológico já apontado, deveria conter em sua essência uma ferramenta variável, instrumento de mediação ante critérios puros de natureza racional-abstrata, demasiado rígidos, portanto, insuficientes ante a heterogeneidade presente na realidade. Busca, na alegoria da Régua de Lesbos, o critério ensejador de correção da lei, a eqüidade capaz de corrigir mesmo ao justo legal. ou seja, a lei geral não pode conter em si toda a realidade prática, ela é sempre deficiente, somente na sua correção via a proporcionalidade eqüânime é possível tal tarefa.

O critério da eqüidade como possibilidade da incidência da Justiça amoldada às particularidades do caso concreto, exige como sucedâneo a

R. Fac. Direito, Curitiba, a. 28, n.28, 1994/95, p. 189-210 
phrónesis, definida como o saber moral de que deve ser dotado aquele que aplica o direito, tal noção, para uma melhor explicação, deve ser compreendida como virtude intelectual e não necessariamente ética, eis um dos muitos pontos que marca o pensamento de Aristóteles como pertecente à corrente do intelectualismo, a phrónesis, não possui especificidade determinada, por isso não está restrita exclusivamente sua aplicação ao direito, muito embora sirva também para utilização neste campo do conhecimento. Sua importância, de qualquer modo é inegável tendo em vista que aquilo que é justo escapa ao teoricamente, ao formalmente, ao logicamente determinado. A situação que exige justiça é dever da pólis proporcionar.

Desse modo, as palavras viajantes que alude Canotilho, acima citado, se adequam à tópica e a phrónesis, como que princípios primeiros a engendrarem uma jurisprudência do caso concreto, provocadas por operadores jurídicos contemporâneos, óbvio que não significa uma transposição mecânica das categorias aristotélicas para nossa época da robótica, da química fina, da engenharia genética, dos novos materiais, mas revisitá-los, integrando-os neste retorno com a produção acumulada pela civilização, recebendo-os de volta, portanto, revificados pela História.

Retira-se assim, um véu epistemológico secular, proporcionando assim uma releitura de Aristóteles, uma vez que este para, distinguia-se na medida que acentuava a importância da experiência prática, da phrónesis, de um saber prudencial meramente aproximativo, em contraste com as pretensões socrático-platônicas de um alcançar um saber absoluto do bem. Em última análise, a "experiência" que constitui o pressuposto da ação moral vem do ethos, do mundo, vivido, das leis e hábitos da Pólis. Para os neo-aristotélicos, não é possível fundar a ética em princípios abstratos, mas somente nas Üblichkeiten, nas práticas habituais da sociedade em que se vive.

O estagirita percebe a razão grega como situada no âmbito do ponderado, é harmonia, daí que a virtude não seja também senão isso - um meio termo mantido entre as várias tendências da natureza humana tidas todas igualmente como boas - esse meio termo métrado na exata medida é a sabédoria, no âmbito da mais elevada virtude entendida como a Justiça, nesse contexto a júris - prudência, adquire relevo especial.

O cosmos grego é indubitavelmente maior que o somatório das partes. Assim, o todo é cronologicamente, ontologicamente e metafisi- 
camente anterior às partes, porém a pólis é o locus da vida política, habitat do homem em sociedade, tanto é que para Aristóteles só os deuses ou as feras podem viver fora da Cidade grega, da pólis enfim.

\section{Padronização, unidade e ruptura no direito}

Observa-se com esse tipo de afirmativa que a lógica da totalidade opera por exclusão-inclusão, o Cosmos grego a tudo inclui, entretanto, a pólis exclui os deuses e os animais, portanto, recebe as mulheres, as crianças e os escravos, enquanto necessários, úteis à Casa, à família, jamais admitidos na cidadania, espaço privilegiado dos varões livres de Atenas.

Esse cambiante conceito, essa palavra viajante chamada de cidadania, utilizada como significante de inclusão do outro, uma vez subvertida a igualdade formal $(\mathrm{A}=\mathrm{A}$ mas também ao mesmo tempo podendo ser $\mathrm{A}$ A), integrando-o a um outro paradigma segundo a proposição o ser é, o não ser pela sua diferença é também, aproxima-se contemporaneamente da compreensão de Dussel no que diz respeito a exterioridade, como categoria conceitual de admissibilidade do outro, pela e por fundamentalmente. diferença que lhe é intrínseca.

$\mathrm{O}$ que pode ser acusado como mais grave em todo o proceder dos juristas consiste num estranho e inexplicável distanciamento da realidade, e na sociedade ocidentalizada em especial de alijamento do outro. Da exclusão mesmo é que se fala, da alteridade do cogito epistemológico. Compreensível se vem do etnocentrismo dos países ricos, porém no terceiro mundo e mais especificamente na América Latina só o preconceito disfarçado e um discurso hipócrita de neutralidade e objetividade da ciência podem justificar tal prática.

Advogando uma ruptura com um tipo de conhecimento e produção subordinada, teólogos, filósofos e operadores jurídicos de uma nova têmpera, sustentam a falência ḑe muitos pressupostos e como tarefa premente a colocação dos problemas até agora discutidos, sob as bases de um novo paradigma, o da alteridade. De onde em primeiro lugar, deve estar o outro com as diferenças que o caracterizam, o que exige um exercício de ruptura pois, para poder ouvir a voz do outro, é necessário que sejamos ateus do sistema ou descobrir seu fetichismo.

R. Fac. Direito, Curitiba, a.28, n.28. 1994/95, p. 189-210 
Em segundo lugar, é necessário respeitar o outro como outro. O respeito é a posição de metafísica passividade com a qual se presta culto a exterioridade do outro: deixa-se que este seja aquilo que é como distinto. O respeito é a atitude metafísica como ponto de partida de toda atividade na justiça. Mas não é respeito à lei (que é universal e abstrata), nem pelo sistema ou seu projeto. É respeito por alguém, pela liberdade do outro. O outro é o único realmente sagrado e digno de respeito sem limite. O respeito é silêncio, mas não silêncio que nada tem a dizer, e sim daquele que tem que escutar tudo, porque nada sabe do outro como outro. ${ }^{17}$

O espaço de inclusão é o da dignidade, no Estado Democrático e de Direito é o do sujeito como cidadão e por decorrência titular de direitos admitidos pela ordem estatal, ou por ele próprio criados na especificidade de sua diferença, que pode ser de dimensão étnica, de gênero, de classe social, e outros mais fatores gestados numa realidade política, social e econômica existente.

\section{Alternatividade e insurgência no direito}

No Brasil cada vez adquire maior visibilidade um movimento que tem posto em xeque os juristas tradicionais, para ser mais preciso, suas concepções teóricas de uma forma ou de outra vinculadas aos dogmas do Direito natural ou do formalismo jurídico, estamos falando de uma Nova Escola Jurídica Brasileira? de Uma Teoria Crítica do Direito? de um Direito Achado na Rua? de um Direito alternativo? ou de um Movimento de um Direito insurgente?

As designações não são consensuais, percebe-se no entanto, que há uma aglutinação em razão das práticas e de um forte sentimento de indignação ante uma realidade de exclusão comum no terceiro mundo, vige um sistema de opressão econômica e social que os teóricos do direito lógicoformais preferiram lançar mão das vendas da deusa Themis, ocorre que dar as costas aos problemas não garante resolução, ao contrário os amplia.

O Direito Alternativo, até agora assim dénominado, é um movimento integrado por magistrados, advogados, promotores, professores e outros

17 Enrique Dussel, Filosofia.... op. cit. p. 65. 
intelectuais que elegeram o direito objeto de investigação ou que numa relação interdisciplinar trabalham próximo ao campo do direito. Esse movimento tem ido além da mera contestação aos pressupostos das arcaicas escolas, anuncia não apenas bandeiras emancipatórias, constata a insuficiência do Estado como única fonte de produção normativa, da impossibilidade de juridicização do mundo e da incapacidade da norma jurídica exclusivamente solucionar os conflitos cotidianos da sociedade, por isso mesmo age com vigor nas mais diferentes esferas do instituído.

Mas estamos realmente observando a germinação de uma nova alternativa? Resposta a essa pergunta está por ser escrita. O que pode ser dito é que o caminho não teve início agora e não se cogita tão cedo na enunciação do seu réquiem, pois sua fonte de germinação está no mundo, e em um terceiro ou último mundo latino americano como é o nosso, proliferam espaços e formas inovadoras de luta, o direito é certamente um deles. Uma breve trajetória nos é descrita por Pressburguer: "Se o uso alternativo do direito teve sua matriz na atuação política dos magistrados italianos; a crítica ao direito (com sua vertente brasileira mais proeminente na NAIR - Nova Escola Jurídica Brasileira de Roberto Lyra Filho) emergiu da produção intelectual de acadêmicos e juristas; o pluralismo jurídico atraiu a atenção dos assessores jurídicos de movimentos sociais; a hermenêutica alternativa (qué se denominou direito alternativo) é atualmente praticada por juízes progressistas; existe um outro direito que permanentemente vai surgindo das necessidades de justiça e do incoformismo de classes subalternas.

O caldo de cultura desse direito insurgente é o conflito social e se revela nas estratégias dos sujeitos coletivos de alguma forma organizados. É aquela "invenção" de um direito mais justo e eficiente, que vai emergindo das lutas sociais, momento histórico e teórico em que os oprimidos se reconhecem como classe distinta daqueles que os oprimem. E este direito, ainda longe de se normatizar ou, kelsenianamente falando, ainda sem eficácia para toda a sociedade, já vai fornecendo indicativos metodológicos na busca de nova metodologia". ${ }^{18}$

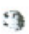

18 Miguel Pressburguer, "Conceitos e Evoluções do Direito Alternativo", in: Anais do Seminário Nacional Sobre o Uso Alternativo do Direito, Rio de Janeiro, IAB/ ADV-COAD, Jun-1993, p. 15.

R. Fac. Direito, Curitiba, a.28, n.28, 1994/95, p. 189-210 
Uma discreta polêmica, em sentido dialético, do afirmar para elevar, tem sido possível observar entre os seguidores da teoria crítica e os alternativos, como verifica-se nessa passagem do constitucionalista Clèmerson Clève:

"Há uma diferença entre o direito alternativo e a antiga teoria crítica do direito. Esta, nascida no seio das Universidades, preocupava-se em desmistificar o fenômeno jurídico através de novos deslocamentos epistemológicos. Tratava-se de um discurso de desconstrução. O direito Alternativo, no Brasil, desenvolveu-se após a imergência desse tipo de teorização e certamente vale-se de sua experiência. Todavia, sua proposta é diferente. Cumpre agora, não apenas criticar o direito posto (discurso da denúncia), mas também contribuir para emergência de um novo direito. $\mathrm{O}$ direito alternativo é um plus em relação à teoria crítica. O Jurista Crítico era um não profissional, na medida em que não advogava, não transitava no foro, não atuava como operador jurídico. Acreditava unicamente na política e na mudança do direito através da política. Isso começa a mudar." ${ }^{19}$

Sem embargo, estamos por concordar com essas diferenças aludidas por esse jurista, entrementes, se os primeiros privilegiaram as Universidades os outros o que já representa um grande salto de qualidade, pois transportaram a luta para o campo nevrálgico do poder - os Tribunais restam enclausurados nos limites do Judiciário. Numa palavra, permanecem no campo do instituído, falamos de uma alternatividade diferente daquela, que apesar dos seus grandes méritos, não superou os umbrais do domínio estatal. Por isso, um e outro têm no direito insurgente um plus face a sutil diferença deste último, ir além dos intelectuais e operadores jurídicos, para encontrar nos próprios excluídos, além de sujeitos de direito, criadores desse mesmo direito. As conquistas não importam no vetor do para os oprimidos, mas de um vetor com os oprimidos, feito em colaboração mesmo, os trabalhadores não estão nem na vanguarda, nem conduzidos a reboque, estão enfim, enxergados e respeitados, como ocupantes do espaço, no qual nunca deixaram de estar, só que agora ombro-a-ombro com seus apoiadores e aliados.

19 Clèmerson Merlin Clève. "A Teoria Constitucional e o Direito Alternativo: Para uma Dogmática Constitucional Emancipatória", in: ANAIS Seminário Nacional Sobre o Uso Alternativo do Direito, op. cit. p. 46. 
Para uma melhor compreensão e muito longe de esgotar o assunto, Paulo Lobo nos apresenta a seguinte tipologia:

1. "O Direito alternativo em sentido estrito toma como ponto de partida o pluralismo jurídico. Valora como jurídicas emanações normativas reconhecidas pelas comunidades, que as praticam consciente ou inconscientemente, mesmo contra o direito oficial, sobretudo quando este é excluído dos grupos sociais dominados.

2. O uso alternativo do direito parte das normas jurídicas reconhecidas pelo Estado, mas segundo uma função social efetiva e. neste sentido, também transformadora e emancipadora. Seu campo é o da aplicação e o da hermenêutica." 20

É sensato indicar tal noção como aquela que recebe uma maior acolhida entre os membros desse movimento, porém, é imperioso fazer menção, mesmo que seja para ampliar a polêmica, de designações que nos parecem fora do contexto mas assumidas em algumas discussões públicas, são as de "positivismo de combate" ou "jusnaturalismo de caminhada", expressões que carregam consigo um assumir envergonhado das velhas Escolas, uma postura vacilante que enseja terminologias híbridas, numa palavra uma impotência no desvencilhamento ao velho. É um primeiro passo, todavia, o novo é exatamente esta incógnita que faz abalar nossas certezas e verdades, tratadas com estima nos mais recônditos lugares do psíquico ou do inconsciente, às vezes por anos a fio.

O que podemos apanhar como distinção basilar, mesmo que superficialmente, é pelo fato do Direito Alternativo, abarcar no seu interior tanto o uso alternativo do direito quanto o direito alternativo em sentido estrito, o primeiro operando no interior do sistema normativo estatal e o segundo supra legem ou mesmo contra legem, recepcionando princípios universalmente consagrados ou vetores axiológicos fruto de acordos e convenções internacionais que vinculam os signatários. Nos parece que o Estado nessa perspectiva é sempre, em linguagem geométrica uma reta, paralela a qual o seu alternativo acompanha ?, se opõe, mas se juntam no infinito.

20 Paulo Luiz Neto Lobo, "Direito Civil Alternativo", in: Lições de Direito Civil Alternativo, São Paulo, Acadêmica, 1994. p. 12.

R. Fac. Direito, Curitiba, a.28, n.28, 1994/95, p. 189-210 
Num Direito Insurgente, existe a perspectiva de rebeldia consigo mesmo, de insurgir-se contra toda a dogmática mesmo que esta vá acomodar-se nesse novo movimento que se inicia, de indignação com a realidade. Sob esta ótica o Estado não é referência, a não ser nos limites de sua plasticidade normativa, que por conquistas dos trabalhadores inscreveram suas reivindicações como normas, mesmo porque, já se constituíam em legítimos direitos antes do estatuto da legalização, pela luta e jamais por natureza.

Entrementes, esse direito insurgente não está simplesmente contra, utilizando-se do ou, ao lado do Estado, pode ser encontrado com existência autônoma em relação ao Estado, sem a desconcertante figura do Tribunal. Opera independentemente, julgando e implementando seu próprio direito, muita das vezes em situação adversa, nos limites da suportabilidade do humano, na qual, prenhe de violências, a única forma de recuperação da dignidade, e encontro real com a cidadania, que nunca conheceu, é encontrada na eliminação do seu algoz, que enfim. está por todos os lados.

Tal trajetória mantém distância, com qualquer qualificação de desumanidade, muito ao contrário, deve ser entendida como a única via, daqueles que buscam a inclusão na sociedade, e o seu próprio reencontro com sua condição de humano. No entanto, constitui-se em ato reprovável e impensável no interior de entidades oficias de ensino e pesquisa, mesmo entre aquelas de caráter humanitário ou confessional, a priori defensoras da vida e contra a barbárie, pois operam numa lógica que os remete à condição de também dominantes do conhecimento civilizado. Embora radical, não se trata de uma opção, mas de atos involuntariamente cometidos nos limites da opressão, por aqueles que sempre viveram sob essa condição. Com fundamento em seus próprios juízos de valor, julgam e executam suas sentenças, única senda capaz de levá-los ao seu direito à liberdade. Isto não é certo ou errado, simplesmente acontece e não pode deixar de ser entendido como direito, exercitado no mais alto grau do estado de necessidade e de legítima defesa individual ou da coletividade a qual pertencem.

\section{Para concluir}

Para concluir, fica o débito de não ter sido realizada uma mais profunda discussão sobre temas atualmente problemáticos, relacionados com origem, designação e contornos teóricos do Movimento do Direito 
Alternativo. Certamente que estão a exigir um estudo acurado que escapa ao alcance deste trabalho. Propositalmente também, deixou-se de aludir às tentativas de uma possível contribuição interdisciplinar entre direito e psicanálise, onde Agostinho Marques, tem sido lido e escutado com vivo interesse, notabilizando-se como o jurista que melhor tratamento tem dado às incursões no campo psicanalítico. ${ }^{21}$

Como contribuição, fica a possibilidade de articulação do pensamento aristotélico com o movimento do Direito Alternativo, que pelas razões elencadas acima preferimos chamar de Direito Insurgente. Nosso entendimento também é a de que seus integrantes dão contornos a um movimento e menos a uma Escola ou teoria acabada, onde são notadas divergências, vitais para a própria existência do grupo, no qual entretanto, se observadas questões de fundo, constata-se há uma certa identidade comum a todos.

Toda essa discussão, não está no terreno da escolástica estéril, vincula-se intrinsecamente a essas novas problemáticas apresentadas pela contemporaneidade, mormente quando dirigimos nossas reflexões aos países pobres como é o caso do Brasil e sobretudo ao outro, ao alter, que está ao nosso lado e não vemos, ou fingimos não ver, aos desvalidos da humanidade, excluídos do sistema político e social, e do mercado de consumo, por isso mesmo tidos como imprestáveis. É fundamentalmente como contributo a estes, em apoio à sua luta, numa perspectiva de alcance da cidadania e da democracia como valores de toda a humanidade, que este trabalho foi elaborado.

\section{Referências Bibliográficas}

ARISTÓTELES. Tópicos; Dos Argumentos Sofisticos. Trad. "Leonel Vallandro e Gerd Borheim." Col. Os Pensadorés. São Paulo: Abril Cultural, 1978.

BARTHES, Roland. Aula. São Paulo: Ed Cultrix, 1978.

21 Sobre o eminente Prof. da Universidade Federal do Maranhão podem ser consultados seus textos em Anais dos Encontros Internacionais de Direito Alternativo promovidos pelo Instituto de Direito Alternativo - IDA e em textos não publicados como é o caso de "Sobre o amor: uma leitura a partir de Freud" lido em Curitiba em 1993. Confira ainda, para a compreensão do sujeito jurídico: uma leitura transdiciplinar". in: Seminário Nacional sobre o uso Alternativo do Direito, Rio de Janeiro, IAB/ADV-COAD (suplemento), Jun-1993.

Fac. Direito, Curitiba, a.28, n.28, 1994/95, p.189-210 
CANOTILHO, José Joaquim Gomes. Direito Constitucional. Coimbra: Almedina, 1992.

CAPRA, Fritjof. O Tao da Física. São Paulo: Cultrix, 1984.

CARVALHO, Paulo de Barros. Curso de Lógica Jurídica. Salvador: Fundação da Universidade Federal da Bahia, 1991.

CLÈVE, Clèmerson Merlin. A Teoria Constitucional e o Direito Alternativo (Para uma Dogmática Constitucional Emancipatória). Rio de Janeiro: IBA/ADV-COAD, 1993.

DUSSEL, Enrique. Filosofia da Libertação na América Latina. São Paulo: Edições Loyola/Ed. Unimep, 1980.

FERRAZ Junior, Tércio Sampaio. Direito, Retórica e Comunicação. São Paulo: Saraiva, 1973. Teoria da Norma Juridica. Rio de Janeiro: Forense, 1986.

Introdução ao Estudo do Direito: Técnica, Decisão e Dominação. São Paulo: Atlas, 1988.

GADAMER, Hans-Georg. Verdad y Método: Fundamentos de Una Hermenéutica Filosófica. 4. ed. Salamanca: Ediciones Sígueme, 1991.

GUIMARÃES, Ruth. Dicionário da Mitologia Grega. São Paulo: Cultrix, 1991.

LOBO, Paulo Luis Neto. "Direito Civil Alternativo." in: Lições de Direito Civil Alternativo. São Paulo: Acadêmica. 1994.

LUDWIG, Celso. A Alternatividade Juridica na Perspectiva da Libertação. Curitiba. 1993. mimeo. (Dissertação de Mestrado à UFPR).

MARQUeS Neto, Agostinho Ramalho. A Ciência do Direito: Conceito, Objeto e Método. Rio de Janeiro: Forense. 1982.

"Para a Compreensão do Sujeito jurídico:" Uma Leitura Transdisciplinar. in: Anais do Seminário Nacional de Direito Alternativo. Rio de Janeiro: IAB/ ADV-COAD. 1993.

Sobre o amor uma leitura a partir de Freud. Curitiba: 1993, mimeo.

- A importância do direito no Brasil de hoje. Aula Inaugural dos Cursos da UFMA no ano de 1993. São Luís: Edufma, 1993.

. A linguagem do poder e o direito. Discurso de Paraninfo, aos concludentes do Curso de Direito da UFMA. São Luis: 1986. mimeo.

MONCADA, Cabral. Filosofia do Direito e do Estado. São Paulo: Saraiva, 1950.

PRESSBURGUER, Miguel. "Conceitos e evoluções do direito alternativo." in: Anais do Seminário Nacional Sobre o Uso Alternativo do Direito. Rio de Janeiro: IAB/ADVCOAD. 1993.

ROUANET, Sérgio Paulo. As Razões do Iluminismo. São Paulo: Companhia das Letras, 1987.

VIEHVEG, Theodor. Tópica e Jurisprudência. Trad. de Tércio Sampaio Ferraz Júnior. Brasília: UNB/Ministério da Justiça, 1979.

VILANOVA, Lourival. Lógica juridica. São Paulo: Ed.'Bushatsky. 1976.

Estruturas lógicas e o sistema de direito positivo. São Paulo: EDUC / Ed. Revista dos Tribunais, 1977.

WARAT, Luís Alberto. O direito e sua linguagem. Porto Alegre: Fabris, 1984.

R. Fac. Direito, Curitiba, a.28, n.28, 1994/95, p. 189-210 